\title{
Design and Evaluation of a Novel Felbinac Transdermal Patch: Combining Ion-Pair and Chemical Enhancer Strategy
}

\author{
Nannan Liu, ${ }^{1}$ Wenting Song, ${ }^{1}$ Tian Song, ${ }^{1}$ and Liang Fang ${ }^{1,2}$
}

Received 14 February 2015; accepted 23 May 2015; published online 13 June 2015

Abstract. The aim of this study was to design a novel felbinac (FEL) patch with significantly higher $(P<0.05)$ skin permeation amount than the commercial product SELTOUCH ${ }^{\mathbb{R}}$ using ion-pair and chemical enhancer strategy, overcoming the disadvantage of the large application area of SELTOUCH ${ }^{\circledR}$. Six complexes of FEL with organic amines diethylamine (DEA), triethylamine (TEA), N-(2'-hydroxyethanol)-piperdine (HEPP), monoethanolamine (MEtA), diethanolamine (DEtA), and triethanolamine (TEtA) were prepared by ion-pair interaction, and their formation were confirmed by differential scanning calorimetry (DSC), powder X-ray diffraction (pXRD), infared spectroscopy (IR), and proton nuclear magnetic resonance spectroscopy ( $\left.{ }^{1} \mathrm{H}-\mathrm{NMR}\right)$. Subsequently, the effect of ion-pair complexes and chemical enhancers were investigated through in vitro and in vivo experiments using rabbit abdominal skin. Results showed that FEL-TEA was the most potential candidate both in isopropyl palmitate (IPP) solution and transdermal patches. Combining use of $10 \% \mathrm{~N}$-dodecylazepan-2-one (Azone), the optimized FEL-TEA patch achieved a flux of $18.29 \pm 2.59 \mu \mathrm{g} / \mathrm{cm}^{2} / \mathrm{h}$, which was twice the amount of the product $\operatorname{SELTOUCH}^{\circledR}\left(J=9.18 \pm 1.26 \mu \mathrm{g} / \mathrm{cm}^{2} / \mathrm{h}\right)$. Similarly, the area under the concentration curve from time 0 to time $t\left(\mathrm{AUC}_{0-t}\right)$ in FEL-TEA patch group $(15.94 \pm 3.58 \mathrm{~h} . \mu \mathrm{g} / \mathrm{mL})$ was also twice as that in SELTOUCH ${ }^{\circledR}$ group $(7.31 \pm 1.16 \mathrm{~h} . \mu \mathrm{g} / \mathrm{mL})$. Furthermore, the in vitro skin permeation results of FEL-TEA patch was found to have a good correlation with the in vivo absorption results in rabbit. These findings indicated that a combination of ion-pair and chemical enhancer strategy could be useful in developing a novel transdermal patch of FEL.

KEY WORDS: chemical enhancer; felbinac-triethylamine (FEL-TEA); in vitro/in vivo correlation (IVIVC); ion-pair; transdermal patch.

\section{INTRODUCTION}

Nowadays, nonsteroidal anti-inflammatory drugs (NSAIDs) remain the most commonly used drugs for treatment of osteoarthritis, rheumatoid arthritis, and acute pain [1]. However, gastrointestinal side effects resulting from repeated oral administration limit their use [2]. As a result, topical products of these drugs, which reduce the risk of gastrointestinal disorders and enhance patients' compliance, have become more and more popular [3].

As a potent NSAID, felbinac (FEL) has been widely used for treatment of osteoarthritis, rheumatoid arthritis, muscle inflammation, and acute soft tissue injuries in topical preparations [4-7]. Currently, FEL patches have been available in Japan and Korea, but the product has a large application area of $70 \mathrm{~cm}^{2}$, which is far beyond the desired size (that is, a surface area of $\leq 40 \mathrm{~cm}^{2}$ ) and decreased patients' compliance [8]. To decrease the large area of the product, the permeation of FEL needs to be further

\footnotetext{
${ }^{1}$ Department of Pharmaceutical Sciences, Shenyang Pharmaceutical University, 103 Wenhua Road, Shenyang, Liaoning 110016, China.

${ }^{2}$ To whom correspondence should be addressed. (e-mail: fangliang2003@yahoo.com)
}

enhanced. Ultrasound therapy was ever used to enhance the effectiveness of FEL gel [9]. However, this method was not especially effective in improving the hydrophilicity of FEL and then increasing the permeability of FEL. Considering the lipophilic property of FEL $(\log P=2.58)$, the partition from lipophilic stratum corneum (SC) to hydrophilic epidermis (ED) may be a principal resistance [10]. Therefore, ion-pair complexation, an effective technique to influence a drug's $\log P$ [11,12], was chosen to decrease FEL's lipophilicity and enhance its permeability. Additionally, chemical enhancer is also a widely used approach to increase the skin permeation of drugs [13]. A combination of chemical enhancer and ion-pair strategy was used to maximize the permeability of ionized drugs [14,15].

In this work, six organic amines, diethylamine (DEA), triethylamine (TEA), $N$-(2'-hydroxy-ethanol)-piperdine (HEPP), monoethanolamine (MEtA), diethanolamine (DEtA), and triethanolamine (TEtA) were selected to prepare ion-pair complexes with FEL, and the different permeation behaviors of these complexes through rabbit abdominal skin were further discussed. On this basis, the skin permeation amount of FEL was further enhanced with combined use of chemical enhancers. Finally, the effect of the combination of ion-pair and chemical enhancer strategy was evaluated both in vitro and in vivo. 


\section{MATERIALS AND METHODS}

\section{Chemicals and Animals}

Felbinac (FEL) was provided by Hubei Xunda Pharmaceuticals Co., Ltd. (Hubei, China). Ethanolamine (MEtA), diethanolamine (DEtA), triethanolamine (TEtA), diethylamine (DEA), triethylamine (TEA), and $N$-(2'-hydroxy-ethanol)-piperdine (HEPP) were purchased from Tianjin Bodi Chemicals Co., Ltd. (Tianjin, China). Isopropyl palmitate (IPP), $\mathrm{N}$-dodecylazepan-2-one (Azone), isopropyl myristate (IPM), Span80 (SP), propylene glycol (PG), and $l$-menthol (MT) were obtained from Alfa Aesar (MA, USA). Duro-Tak ${ }^{\circledR}$ 87-4098 (PSA) was purchased from Henkel Corp. (NJ, USA). Methanol of HPLC grade was supplied by the Hanbang Science and Technology Co., Ltd. (Jiangsu, China). SELTOUCH ${ }^{\circledR}$ tape 70 (felbinac, $70 \mathrm{mg} / 140 \mathrm{~cm}^{2}$ ) was obtained from Teikoku Seiyaku Co., Ltd. (Osaka, Japan). All other chemicals were of analytical grade.

Male rabbits weighing $1.8-2.2 \mathrm{~kg}$ were supplied by the Experimental Animal Center of Shenyang Pharmaceutical University (Shenyang, China). All animal experiments were performed according to the NIH Guidelines for the Care and Use of Laboratory Animals as well as the guidelines for animal use published by the Life Science Research Center of Shenyang Pharmaceutical University.

\section{Preparation and Characterization}

\section{Preparation of Ion-Pair Complexes}

Equimolar amount of FEL and organic amines were dissolved in ethanol and stirred for $2 \mathrm{~h}$. Then, the solvent was removed using a rotary evaporator, and products were obtained after drying in a vacuum for $24 \mathrm{~h}$.

\section{DSC and $p X R D$ Characterization}

Subsequently, FEL and its solid complexes were identified by differential scanning calorimetry (DSC) and powder X-ray diffraction ( $\mathrm{pXRD}$ ). The pXRD patterns of samples were measured with DX-2700 XRD diffractometer (Dandong, China) using $\mathrm{Cu} \mathrm{K} \alpha$ radiation (tube operated at $40 \mathrm{kV}$, $40 \mathrm{~mA}$ ). Data were collected over the $2 \theta$ range of $3-50^{\circ}$.

\section{IR and ${ }^{1} \mathrm{H}-\mathrm{NMR}$ Characterization}

FEL and its complexes were also characterized by infrared spectra (IR) and ${ }^{1} \mathrm{H}-\mathrm{NMR}$. For ${ }^{1} \mathrm{H}-\mathrm{NMR}$ study, samples were dissolved into deuterated chloroform $\left(\mathrm{CDCl}_{3}\right)$ and analyzed with an Advance-400 MHz instrument (Bruker, Germany). Chemical shifts $(\delta)$ for $\mathrm{CH}$ groups were reported in parts per million relative to tetramethylsilane.

\section{Preparation of Patches}

FEL or its ion-pair complexes equivalent to the amount of FEL, penetration enhancers and pressure sensitive adhesive (PSA) were dissolved in ethanol and mixed thoroughly with a magnetic bar. The resulting mixture was then coated onto a release linear followed by drying at $50^{\circ} \mathrm{C}$ for $20 \mathrm{~min}$. After removal of the solvent, the products were covered with backing membranes.

\section{In Vitro Studies}

\section{Apparent Partition Coefficient Experiments}

The apparent partition coefficients of FEL and its complexes were measured by the classic shake-flask method [16]. Equal volumes of distilled water and $n$-octanol and an appropriate amount of drugs were added into a sealed glass vial and agitated to achieve equilibrium at $32^{\circ} \mathrm{C}$ for $48 \mathrm{~h}$. After centrifugation, the sample concentration in each phase was determined by HPLC.

\section{Apparent Solubility Measurements}

The solubilities of FEL and its complexes in IPP solutions were determined at $32^{\circ} \mathrm{C}$, by adding excessive drugs to the vehicle in glass vials. All vials were shaken for $48 \mathrm{~h}$ until equilibrium. After centrifugation and dilution, the concentration of each drug was determined by HPLC.

\section{In Vitro Skin Permeation Experiments}

Excised rabbit abdominal skin was used to evaluate the skin permeation of FEL and its ion-pair complexes and prepared according to a previous report [14]. In vitro skin permeation experiments were performed using twochamber side-by-side glass diffusion cells. The excised rabbit skin was mounted between the diffusion cells, with dermal side facing the receptor compartment. The receptor cell was filled with $3 \mathrm{~mL}$ pH 7.4 phosphate buffer (PBS), and the donor cell was suspensions composed of FEL or its ion-pair complexes in IPP. For the skin permeation experiments from patches, donor compartments were exchanged to patches stuck on the SC side of skin. Solutions in both compartments were stirred at about $600 \mathrm{rpm}$ and maintained at $32^{\circ} \mathrm{C}$. At pre-determined time intervals, $2 \mathrm{~mL}$ samples were withdrawn from the receptor compartment for analysis, and then an equal volume of fresh receptor medium was added to maintain the constant volume. The samples were analyzed by HPLC method.

The cumulative amount of each drug permeating per unit area $(Q)$ versus time was plotted. The steady-state flux $(J, \mu \mathrm{g} /$ $\mathrm{cm}^{2} / \mathrm{h}$ ) was calculated from the slope of linear region of the plot. The enhancement ratio $(E R)$ was defined as $Q$ for the ion-pair group or enhancer-containing group divided by the same parameter for the control group containing only FEL or FEL-TEA.

\section{In Vivo Studies}

\section{Rabbit Skin Irritation Test}

Four healthy rabbits were used to test the skin irritation of FEL-TEA patch according to the Draize method [17]. One day prior to the experiment, each rabbit abdominal skin was 
shaved and divided into four areas. Each area was grouped and treated as follows:

- Control group-non-treated

- Positive group—standard irritant (10\% aqueous solution of lauryl sodium sulfate)

- Negative group-blank patch $\left(6 \mathrm{~cm}^{2}\right.$, without any drug)

- FEL-TEA group-the optimized FEL-TEA patch $\left(6 \mathrm{~cm}^{2}\right)$

Then patches were removed after a period of $12 \mathrm{~h}$, and the resulting reactions (erythema and edema) after removing patches at 24,48 , and $72 \mathrm{~h}$ were evaluated by a scale of scores as follows:

0.0 0.4: negligible response;

0.5 1.9: slight response;

2.0 4.9: moderate response;

5.0 8.0: severe response.

\section{Administration and Sampling}

Twelve male rabbits weighing $1.8-2.2 \mathrm{~kg}$ were randomly divided into two groups, and the day prior to the experiments, an abdominal area of about $48 \mathrm{~cm}^{2}$ was shaved carefully without damaging the skin. For group A, rabbits were treated with the commercial product SELTOUCH $^{\circledR}\left(\right.$ FEL, $\left.0.5 \mathrm{mg} / \mathrm{cm}^{2}\right)$ on the abdominal area for $12 \mathrm{~h}$. For comparison, animals in group B were applied with the optimized FEL-TEA patch (equals to FEL $0.5 \mathrm{mg} / \mathrm{cm}^{2}$ ) on the same area. Blood samples were collected at $0.083,0.167,0.5,1,2,3,4,6,8,10,12$, and $14 \mathrm{~h}$ after transdermal administration. After a washout period of 2 days, rabbits in group B were given an intravenous administration of FEL-TEA (equals to FEL $4 \mathrm{mg} / \mathrm{kg}$ ) via the marginal ear vein, and blood samples were collected at $0.083,0.167,0.25,0.5,0.75,1,2,3,4,5$, and $6 \mathrm{~h}$ after intravenous administration. Plasma were obtained by centrifugation at $16,000 \mathrm{rpm}$ for $5 \mathrm{~min}$ and stored at $-70^{\circ} \mathrm{C}$ until analysis.

\section{Treatment and Analysis of Plasma Samples}

A $100 \mu \mathrm{L}$ aliquot of rabbit plasma was mixed with $10 \mu \mathrm{L}$ ethylparaben solution and $10 \mu \mathrm{L} 1 \mathrm{~mol} / \mathrm{L}$ hydrochloric acid before extracted with $1 \mathrm{~mL}$ ethyl acetate by vortex for $10 \mathrm{~min}$. The mixture was centrifuged at $16,000 \mathrm{rpm}$ for $5 \mathrm{~min}$, and the organic layer was transferred to another tube and evaporated under nitrogen at $40^{\circ} \mathrm{C}$. Then, the residue was reconstituted in $100 \mu \mathrm{L}$ mobile phase and centrifuged at $16,000 \mathrm{rpm}$ for $5 \mathrm{~min}$. A $20 \mu \mathrm{L}$ aliquot of supernatant was injected into the HPLC system for analysis.

\section{Pharmacokinetic Analysis}

The peak blood concentration $\left(C_{\max }\right)$ was obtained directly from the concentration-time profile. The area under the concentration curve from time 0 to time $t$ $\left(\mathrm{AUC}_{0-t}\right)$, and the mean residence time (MRT) were obtained by noncompartmental analyses with the help of WinNonlin ${ }^{\circledR}$.

\section{In Vitro/In Vivo Correlation}

The predicted in vitro skin permeation profiles of FEL-TEA transdermal patches in rabbits were obtained using the following formula as described in a previous study [18].

$C(t)=\int_{0}^{t} I(\theta) W(t-\theta) d \theta=I(\theta) * W(\theta)$

where $C(t), I$, and $W$ are the plasma concentration in rabbit as a function of time, the input into the system (i.e., in vitro skin permeation results), and the weighting function (i.e., intravenous data), respectively. And * stands for the convolution operator. Therefore, $I(t)$, the in vitro permeation results of FEL-TEA patch, can be predicted from the in vivo absorption data and intravenous data by the deconvolution method.

$\boldsymbol{I}(\boldsymbol{t})=\boldsymbol{R}(\boldsymbol{\theta}) / / \boldsymbol{W}(\boldsymbol{\theta})$

where the symbol // denotes the deconvolution operation.

\section{Quantitative Analysis}

The amounts of FEL and its complexes were determined by HPLC. The HPLC system consists of an L-2130 pump (Hitachi Ltd., Japan), an L-2420 variable wavelength ultraviolet absorption detector (Hitachi Ltd., Japan), and an HT-220A chromatographic column incubator (Dalian Huida Scientific instruments, Ltd.). Chromatographic separation was achieved on Diamonsil C18 column, $200 \mathrm{~mm} \times 4.6 \mathrm{~mm} \times 5 \mu \mathrm{m}$, by using a mobile phase containing methanol: $0.02 \mathrm{~mol} / \mathrm{L} \mathrm{pH} 4.5 \mathrm{NH}_{4} \mathrm{Ac}-$ HAc buffer solution $(75: 25, v / v)$ at a flow rate of $1 \mathrm{~mL} /$ min. Ethylparaben was used as the internal standard and detection wavelength was set at $254 \mathrm{~nm}$.

\section{Data Analysis}

Each experimental value was an average of minimum four measurements. Statistical analysis was conducted by using Student's $t$ test and all data were presented as mean \pm standard deviation (SD). A difference between data was considered significant when $P<0.05$.

\section{RESULTS AND DISCUSSION}

\section{Characterization of FEL Ion-Pair Complexes}

\section{DSC and $p X R D$ Characterization}

All FEL complexes were characterized by DSC and pXRD, except for FEL-HEPP in the sticky liquid state. As presented in Fig. 1, FEL had a sharp endothermic peak at $160^{\circ} \mathrm{C}$, and all FEL complexes had lower melting temperatures. According to literatures [19], it was probably due to the different arrangement of molecules in the crystal lattice, and FEL complexes may have 


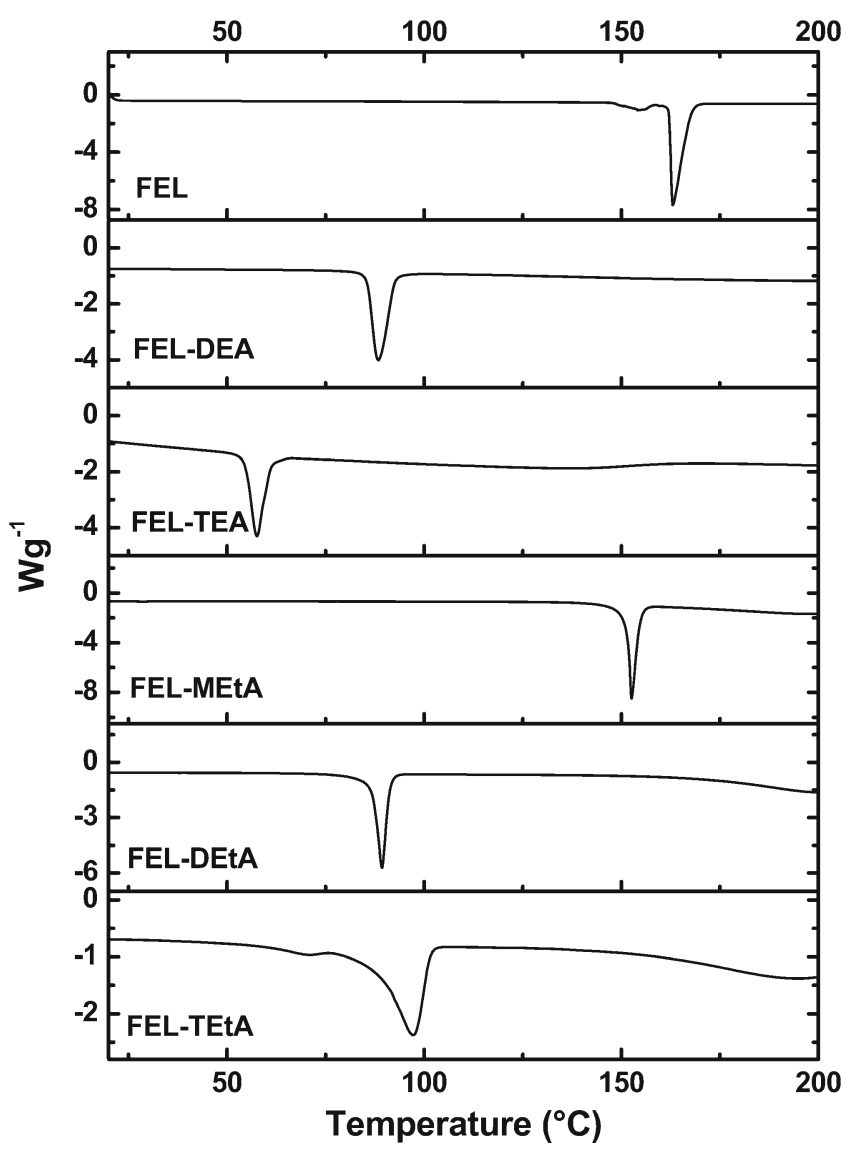

Fig. 1. DSC curves of felbinac and its ion-pair complexes at a heating rate of $10^{\circ} \mathrm{C} / \mathrm{min}$

lower crystalline lattice energy [20]. Figure 2 showed the pXRD patterns of solid-state forms of FEL and its complexes. The distinct differences in the diffraction patterns of FEL and its complexes also demonstrated the different arrangement of molecules in the crystal lattice [21].

\section{IR and ${ }^{1} H-N M R$ Characterization}

Infrared spectroscopy (IR) plays an important role in studying the formation of ion pairs [22,23]. In IR spectrum of FEL (Fig. 3), the absorption at $1687 \mathrm{~cm}^{-1}$ was assigned to the stretching vibration of $\mathrm{C}=\mathrm{O}$ group. In the case of $\mathrm{FEL}$ complexes with MEtA, DEtA, TEtA, and HEPP, the absorption at $1687 \mathrm{~cm}^{-1}$ was red shifted to $1581,1634,1588$, and $1580 \mathrm{~cm}^{-1}$, respectively, and that red shift was reckoned as a criterion for hydrogen bonding [22]. Contrary to the above complexes, the $\mathrm{C}=\mathrm{O}$ stretching bands in FEL complexes with DEA and TEA got blue shifted to 1700 and $1693 \mathrm{~cm}^{-1}$, separately. This phenomenon was not contradictive to the aforementioned redshift criterion. As the carboxylic acid groups in FEL can form dimers by the intermolecular hydrogen bonding [24], the $\mathrm{R}_{3}-\mathrm{N}$ acceptor groups in DEA and TEA might disrupt the original intermolecular hydrogen bond due to the formation of new intermolecular hydrogen bond with the carboxyl donor groups in FEL. Based on literatures [25], it could be inferred that the electronegativity of $\mathrm{R}_{3}-\mathrm{N}$ acceptor groups in DEA and TEA were weaker than

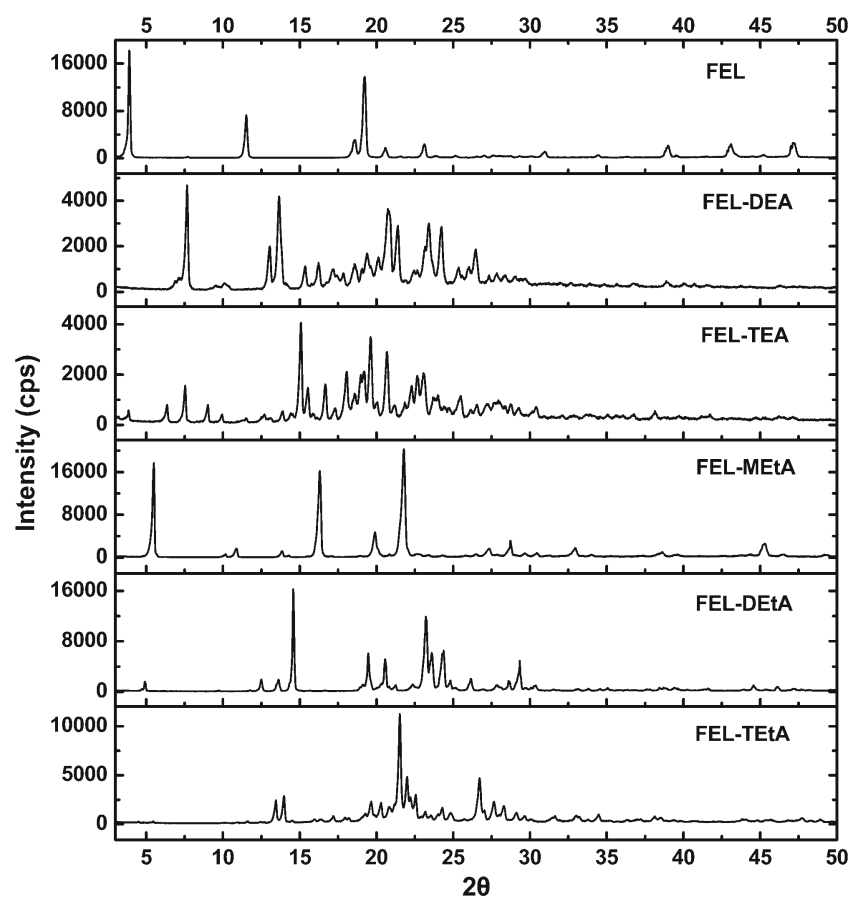

Fig. 2. Powder X-ray diffractograms of FEL and its ion-pair complexes

that of $\mathrm{C}=\mathrm{O}$ acceptor groups in FEL, thus leading to the electron redistribution of the corresponding carboxyl group acted as a donor group and the blue shift of $\mathrm{C}=\mathrm{O}$ stretching vibration in this group $[23,26]$. This explanation also conformed to the proton-transfer model of Huyskens and Zeegers-Huyskens [27], which showed that the larger $\mathrm{pKa}$ difference between the proton donor (FEL) and acceptor

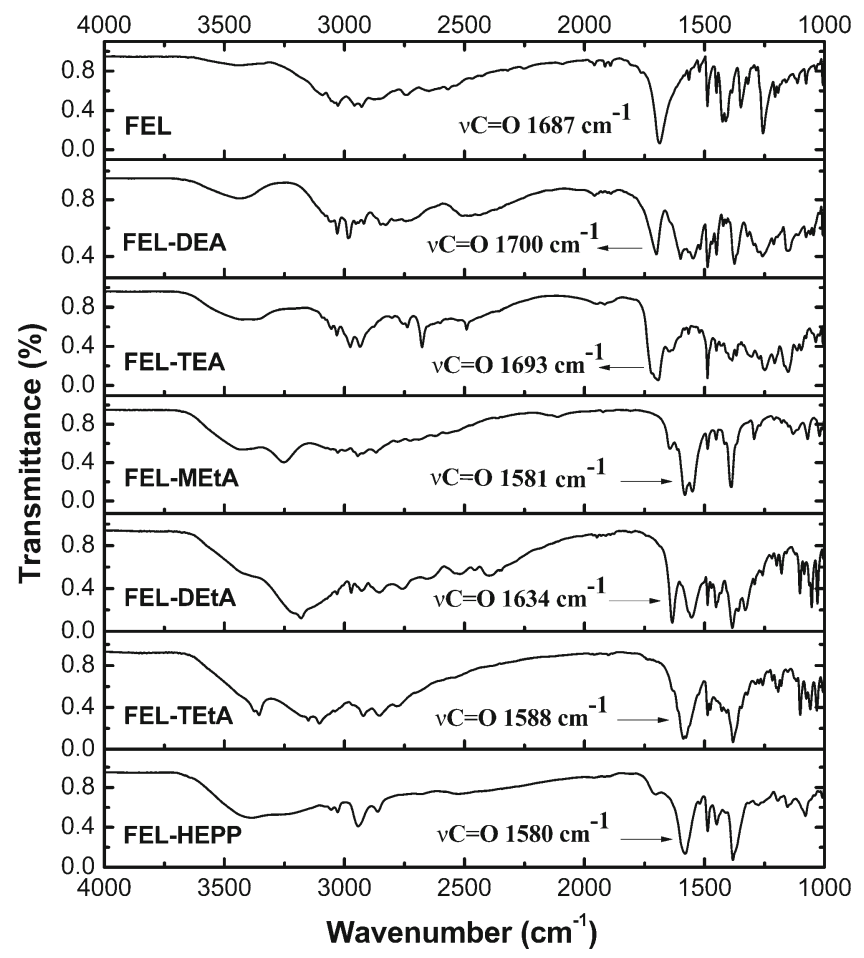

Fig. 3. IR spectra of felbinac and its ion-pair complexes 
Table I. ${ }^{1} \mathrm{H}$ NMR Chemical Shifts of FEL and Its Ion-Pair Complexes for Proton on Carbon

\begin{tabular}{llcccrrr}
\hline Permeants & FEL & FEL-DEA & FEL-TEA & FEL-MEtA & FEL-DEtA & FEL-TEtA & FEL-HEPP \\
\hline$\delta(\mathrm{ppm})$ & 3.72 & 3.63 & 3.64 & 3.60 & 3.58 & 3.66 \\
$\Delta \delta(\mathrm{ppm})$ & 0 & -0.09 & -0.08 & -0.12 & -0.14 & -0.06 & -0.10 \\
\hline
\end{tabular}

(DEA and TEA) indicated stronger hydrogen bond interaction.

NMR spectroscopy also offered a good evidence for hydrogen bonding and was therefore used to analyze the interaction between FEL and organic amines in IPP, based on the chemical shift change of the methenyl proton near the carboxyl group. However, the complicated structure of IPP interfered the spectra of samples, deuterated chloroform $\left(\varepsilon_{\mathrm{r}}=4.81\right)$ was chosen as substitutions of IPP $\left(\varepsilon_{\mathrm{r}}=3.18\right)$ based on its comparable dielectric constant [23]. As illustrated in Table I, the signal of the methenyl proton in all complexes brought out upfield shifts compared with that in FEL. It could be elucidated that there existed hydrogen interactions between FEL and organic amines. In detail, the carboxyl group of FEL had an electrophilic effect on methenyl, which decreased the electron atmosphere density and caused a downfield shift of the methenyl proton. After the introduction of organic amines, hydrogen bond was formed between the carboxyl group of FEL and the basic organic amine, which impaired the deshielding effect and brought out an upfield shift of the methenyl proton [28]. In a word, all characterization results demonstrated the formation of FEL ionpair complexes.

\section{In Vitro Evaluation}

\section{The Effect of Organic Amines on the Skin Permeation of FEL}

As FEL is a weak acid, six organic amines were chosen to prepare ion-pair complexes with FEL and the permeation of these complexes from both IPP and transdermal patches were investigated. IPP is a frequently used cosmetic ingredient with low dielectric constant $\left(\varepsilon_{\mathrm{r}}=3.18\right)$, which can contribute to the formation of ion pairs and simulate the highly lipophilic matrix such as pressuresensitive adhesives [23,29]. Different from the permeation experiments from patches, the permeation experiment from IPP ignores the influence of patch matrix; thus, the flux from IPP can represent the skin permeability of drugs to some extent. The permeation profiles from IPP and relevant parameters are presented in Fig. 4 and Table II. As depicted in Fig. 4, TEA, DEA, and HEPP had a positive effect on the permeation of FEL, and among them, TEA had the greatest enhancing effect, while other amines, i.e., TEtA, MEtA, and DEtA, exerted negative effects. The different effects of amines can be explained by the altered physicochemical properties of a drug due to the formation of ion-pair complexes [30].

As illustrated in Fig. 5a, the flux of FEL ion-pair complexes increased with the increasing solubility $(r=0.9929)$, which indicated that solubility was an important factor affecting their permeation rate [31]. However, for FEL-DEA and FEL-HEPP, the introduction of amines did not increase their solubility, but their flux was increased. This suggested that the flux increase of these FEL complexes could be attributed in part to their different solubility in the donor phase and there existed other factors affecting their flux [32]. In Fig. 5b, the flux also increased with the increasing $n$-octanol/water partition coefficient $\log P$ of FEL ion-pair complexes ( $r=0.9498)$. This suggested Log $P$ might be another important factor. According to the two-layer skin model [10], the simplified skin consists of a lipophilic SC and an underlying hydrophilic ED. For hydrophilic drugs, the lipophilic SC layer provides a main barrier. While for lipophilic drugs, the partition from SC to hydrophilic ED becomes a ratelimiting step. Thus, to achieve enhanced skin permeability, drugs should possess balanced lipid and water solubility. As a lipophilic drug, FEL is almost insoluble in water and the distribution from SC to ED may be a principal resistance. With the help of organic amines like TEA, DEA, and HEPP, the lipophilicity of FEL decreased to a suitable level, making it easier to partition into the ED and thereby brought about an enhanced permeability. In contrast, FEL complexes with MEtA, DEtA, and TEtA exhibited lower permeation than FEL. It may also be due to the altered solubility and $\log P$ of FEL complexes. As can be seen from Table II, the flux of FEL complexes with MEtA, DEtA, and TEtA decreased as their decreasing solubility in donor phase. This indicated that solubility was an important factor affecting the flux of FEL complexes. Meanwhile, the lipophilicity of these complexes also influenced their permeability. As MEtA, DEtA, and TEtA had strong hydrophilicity, the introduction of these amines greatly reduced the lipophilicity of FEL even to

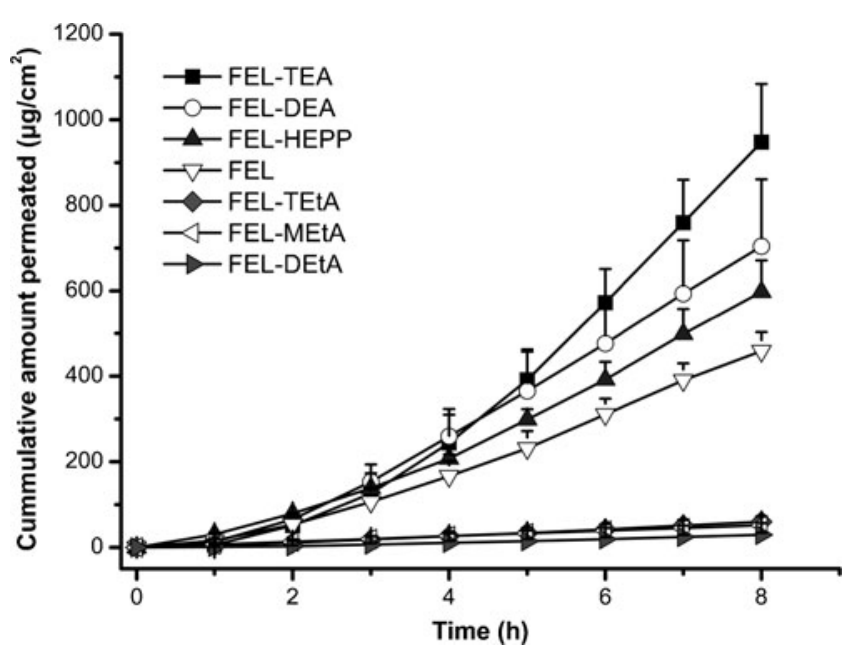

Fig. 4. Effect of ion-pair complexes on the permeation of felbinac from IPP $(n=4)$ 
Table II. Permeation Parameters of FEL and Its Ion-Pair Complexes from IPP Through Rabbit Abdominal Skin $(n=4)$ and Corresponding Physicochemical Properties

\begin{tabular}{|c|c|c|c|c|c|c|}
\hline Permeants & $\log P_{\text {amines }}$ & $\log P_{\text {ion pairs }}$ & $\mathrm{S}^{a}(\mathrm{mg} / \mathrm{mL})$ & $\mathrm{S}^{b}(\mathrm{mg} / \mathrm{mL})$ & $\mathrm{p} K \mathrm{a}$ & $J\left(\mu \mathrm{g} / \mathrm{cm}^{2} / \mathrm{h}\right)$ \\
\hline FEL-TEA & 1.65 & 0.81 & $3.50 \pm 0.28$ & $6.50 \pm 0.43$ & 10.62 & $177.60 \pm 32.21$ \\
\hline FEL-DEA & 0.66 & 0.36 & $2.40 \pm 0.07$ & $9.27 \pm 0.48$ & 10.76 & $111.86 \pm 22.54$ \\
\hline FEL-HEPP & 0.50 & 0.30 & $2.37 \pm 0.07$ & $178.24 \pm 2.71$ & 8.96 & $94.03 \pm 15.45$ \\
\hline FEL & - & 2.58 & $3.05 \pm 0.03$ & $5.26 \pm 0.06$ & - & $74.35 \pm 6.13$ \\
\hline FEL-TEtA & -0.99 & -0.02 & $0.29 \pm 0.02$ & $21.25 \pm 2.32$ & 7.77 & $8.45 \pm 0.48$ \\
\hline FEL-MEtA & -1.76 & -0.38 & $0.19 \pm 0.01$ & $19.66 \pm 2.31$ & 8.71 & $6.32 \pm 0.60$ \\
\hline FEL-DEtA & -1.48 & -0.52 & $0.02 \pm 0.01$ & $35.68 \pm 1.61$ & 9.16 & $4.72 \pm 0.16$ \\
\hline
\end{tabular}

${ }^{a}$ Solubility in isopropyl palmitate (IPP)

${ }^{b}$ Solubility in phosphate buffer ( $\left.\mathrm{pH} 7.4\right)$

become hydrophilic. That hydrophilic character hindered their partition into the lipophilic SC layer, thus presenting a negative effect. Therefore, both solubility and $\log P$ had a major influence on the flux of FEL ion-pair complexes, and those organic amines which could alter the $\log P$ of a drug to a proper level would have a positive effect on the drug's permeability.

In addition, the $\mathrm{pKa}$ of counter ions was reckoned as another factor affecting the permeability of ion pairs in previous reports. The fluxes of flurbiprofen ion pairs were found to increase with the increasing $\mathrm{pKa}$ values of amines and this was attributed to the stronger attractive force between flurbiprofen and amines [28]. Xi et al. also demonstrated that $\mathrm{pKa}$ of counter ions could affect the stability of their ion pairs, thus influencing the permeability of ion pairs [23]. Although amines with relatively high $\mathrm{pKa}$ exhibited enhancing effect on FEL, the correlation between the flux of FEL complexes and $\mathrm{pKa}$ of amines was not quite so successful $(r=0.7998)$, probably because

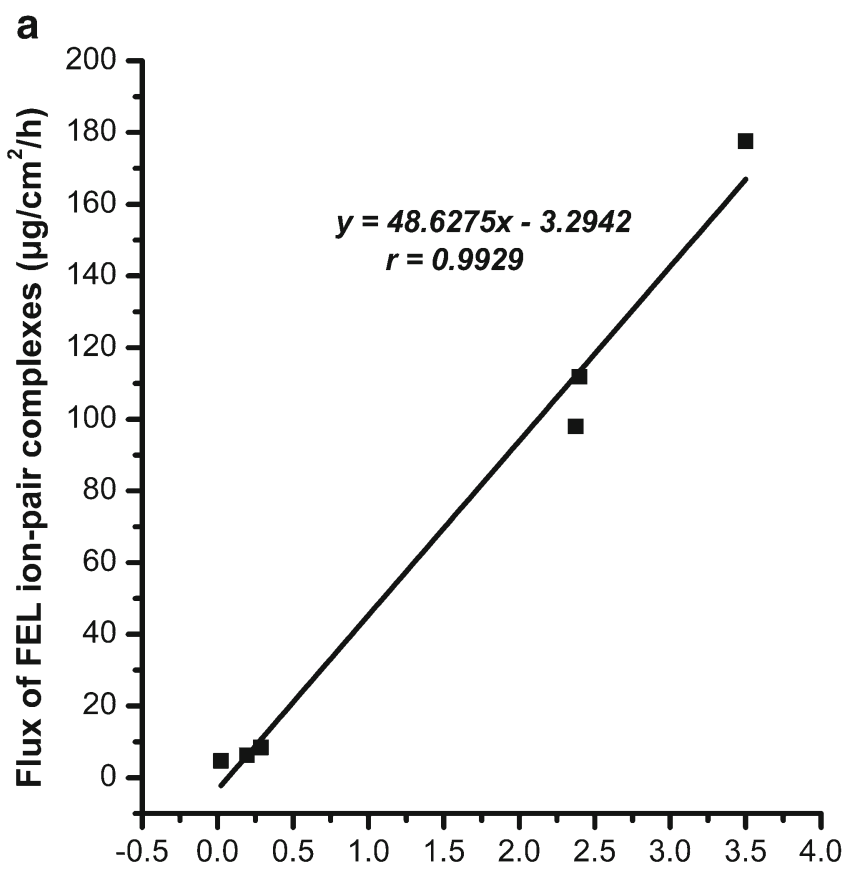

Solubility of FEL ion-pair complexes $(\mathrm{mg} / \mathrm{mL})$ the different fluxes of ion-pairs were influenced by several factors together including both parent drugs and counterions. But this $\mathrm{pKa}$ effect can still be seen in TEA and DEA, with relatively higher $\mathrm{pKa}, \mathrm{DEA}$, and TEA also exhibited significantly promoting effect on FEL, and this may also be due to their stronger attractive force and more stable formation of complexes with FEL [27]. This explanation was also consistent with the IR results, in which the red-shift phenomenon in TEA and DEA suggested their stronger interaction with FEL.

In transdermal patches, ion-pair strategy was also used due to the promoting effect of TEA, DEA, and HEPP in IPP solution system. PSA Duro-Tak ${ }^{\circledR}$ 87-4098 without functional groups was used to prepare transdermal patches, thus avoiding the polar functional groups' damage to ion-pair structure. As shown in Figs. 6 and 7, the order of the permeation amounts of FEL ion-pair complexes from patches was almost the same as that from IPP solution $(r=0.9762)$. That means the lipophilic IPP

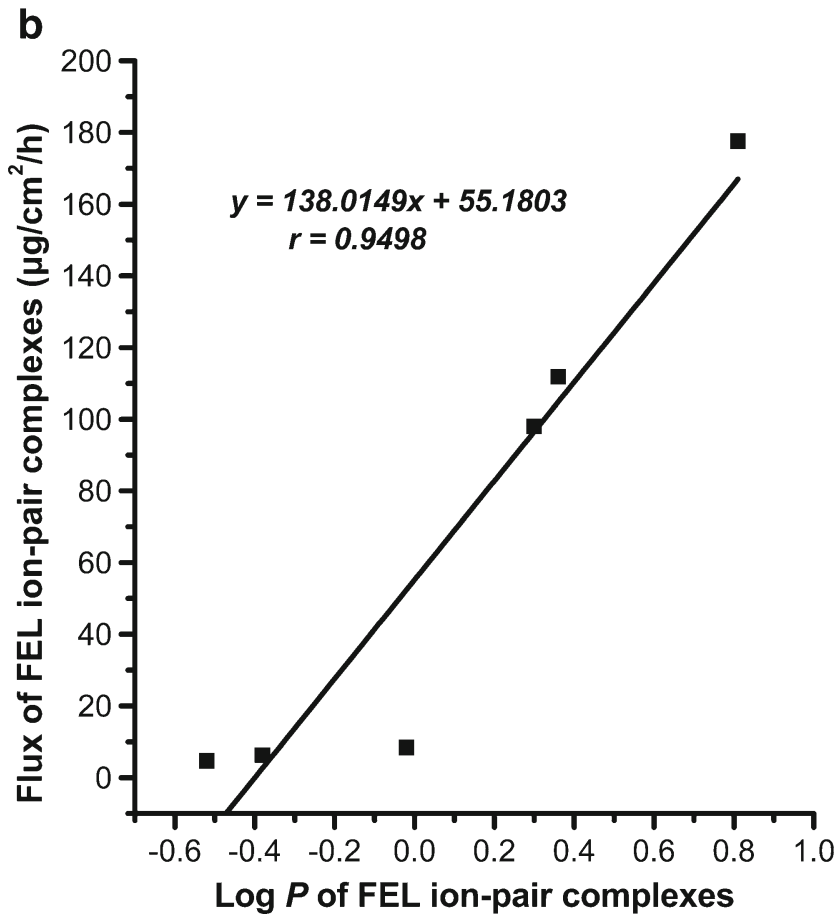

Fig. 5. a Relationship between the flux of FEL ion-pair complexes from IPP and their solubility in IPP. b Relationship between the flux of FEL ion-pair complexes from IPP and $\log P$ of these complexes 


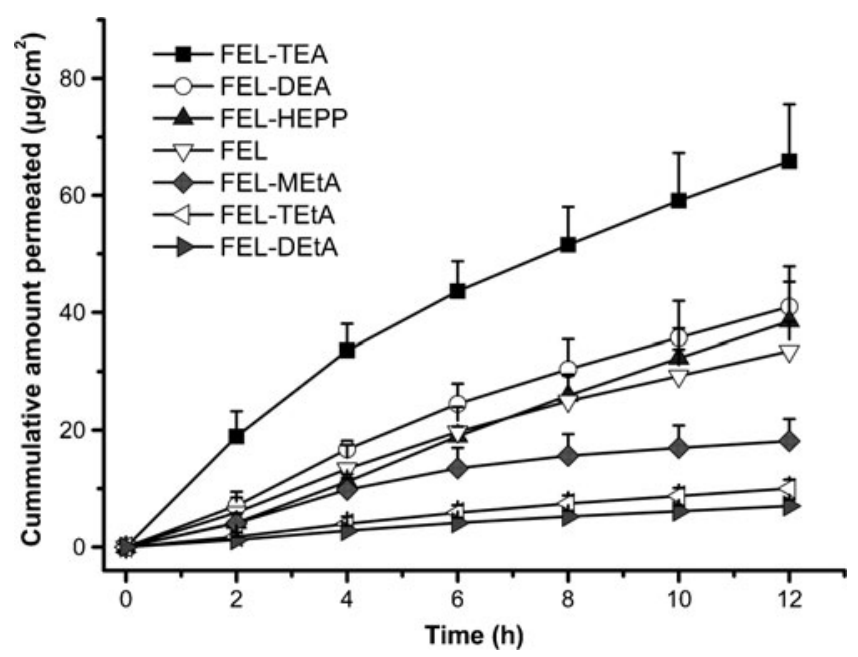

Fig. 6. Effect of ion-pair complexes on the permeation of felbinac from transdermal patches $(n=4)$

solution system can predict the permeation of drugs from patches prepared with lipophilic PSA Duro-Tak ${ }^{\circledR}$ 87-4098. In PSA, FEL-TEA $(5 \%, w / w$, based on adhesive weight) still had the highest flux $\left(J=6.07 \pm 1.11 \mu \mathrm{g} / \mathrm{cm}^{2} / \mathrm{h}\right)$, which was significantly higher than that of FEL $(J=3.16$ $\pm 0.36 \mu \mathrm{g} / \mathrm{cm}^{2} / \mathrm{h}$ ). This indicated the feasibility of ion-pair strategy used in transdermal patches, and therefore, FELTEA was used to substitute FEL for designing a more effective transdermal patch.

\section{Combined Effect of Chemical Enhancers}

To further increase the cumulative amounts of FEL-TEA patch, chemical enhancer was introduced and combined with ion-pair strategy in this study [33]. $\mathrm{N}$-Dodecylazepan-2-one (Azone), isopropyl myristate (IPM), Span80 (SP), propylene glycol (PG), and $l$-menthol (MT), five commonly used penetration enhancers known to be safe or used commercially $[13,34,35]$, were

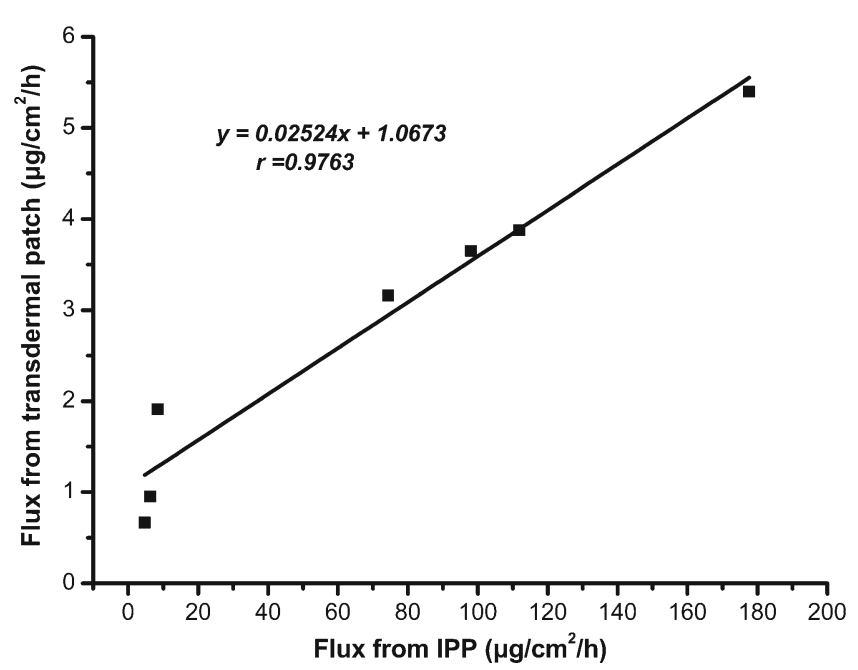

Fig. 7. Relationship between the flux from transdermal patches and the flux from IPP of FEL and its ion-pair complexes

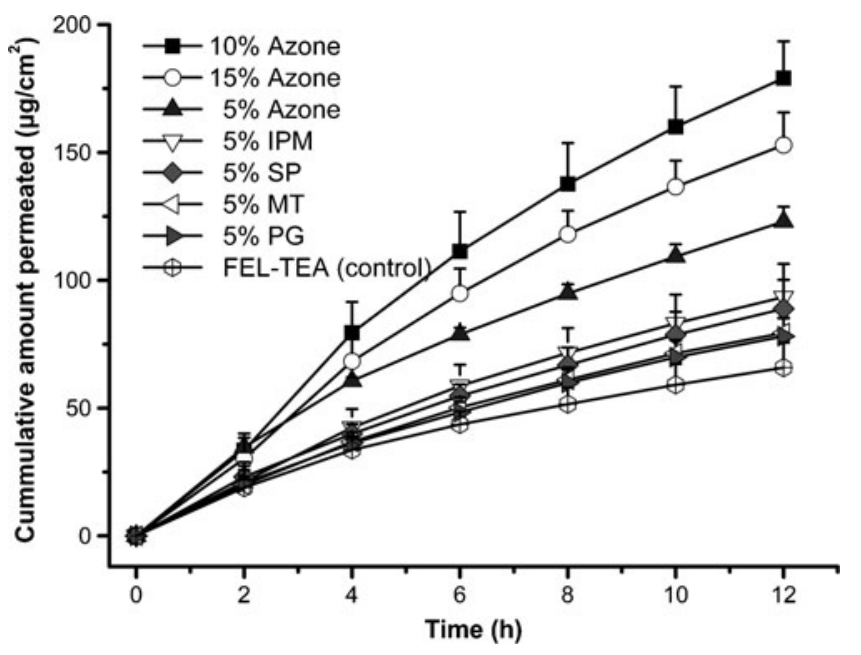

Fig. 8. Effect of chemical enhancers on the permeation of FEL-TEA from transdermal patches $(n=4)$

used and the concentration of enhancers was initially fixed at $5 \%(w / w)$.

As shown in Fig. 8, the relatively lipophilic enhancers Azone $(\log P=6.02$, obtained from SciFinder database) and IPM ( $\log P=7.25$, obtained from Hui M et al. 2014) had greater enhancement effect on the permeation of FEL-TEA, and Azone had the greatest promoting effect $(P<0.05)$. It has been widely accepted that the predominant route of penetration is through the intercellular lipid domains [34]; therefore, these results suggested lipophilic enhancers could partition well into the modified SC. Furthermore, Azone was reckoned to exert its enhancing effect by partitioning into stratum corneum and disrupting the packings of the bilayer lipids $[13,36]$. Subsequently, the influence of Azone concentration was further studied. As illustrated in Fig. 8, the permeation amount of FEL-TEA increased as the concentration of Azone increased from 5 to $10 \%$, but when it increased to $15 \%$, the permeation of FEL-TEA was

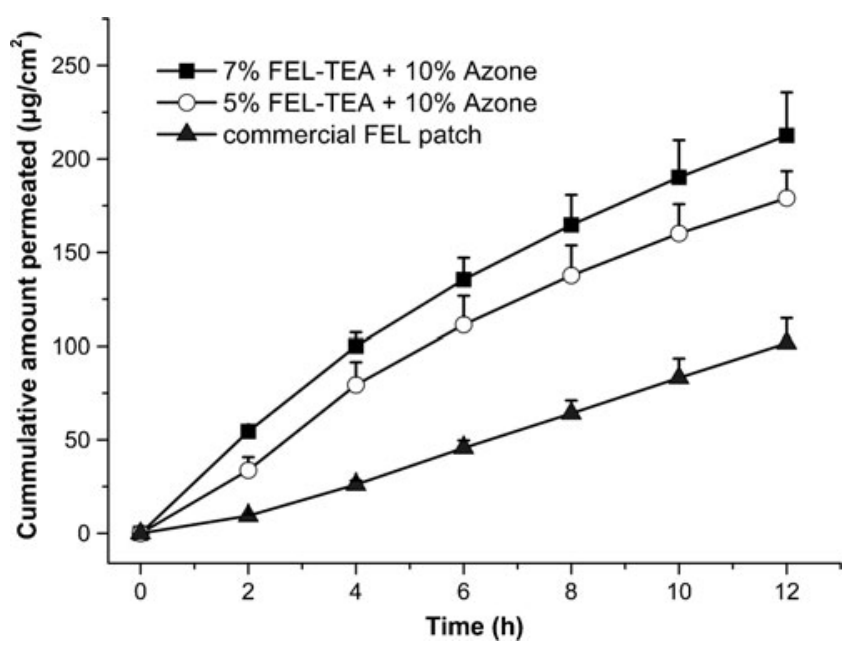

Fig. 9. The penetration profiles of patches containing different concentration of FEL-TEA and compared with the commercial FEL patch $(n=4)$ 
Table III. Results of Rabbit Skin Irritation Test $(n=4)$

\begin{tabular}{llll}
\hline Treatment & $24 \mathrm{~h}$ & $48 \mathrm{~h}$ & $72 \mathrm{~h}$ \\
\hline FEL-TEA patch & $0.25 \pm 0.10$ & 0.0 & 0.0 \\
Standard irritant & $6.17 \pm 0.19$ & $6.56 \pm 0.19$ & $7.67 \pm 0.50$ \\
\hline
\end{tabular}

not further increased. This could be explained by the effect of Azone on the hydration of SC, which had a negative influence on the partition of FEL-TEA [37,38]. Overall, 10\% Azone had the greatest enhancement effect on FEL-TEA and it was chosen for designing the formulation of FEL-TEA patch.

To make the skin permeation results comparable with the commercial product, the concentration of FEL-TEA in the optimized patch was increased to $7 \%$, which equaled to the amount of FEL in the product SELTOUCH ${ }^{\circledR}\left(0.5 \mathrm{mg} / \mathrm{cm}^{2}\right)$. As shown in Fig. 9 , the flux of the optimized patch containing 7\% FEL-TEA was significantly higher than that of the commercial product. The in vitro evaluation results indicated that it was useful to maximize the flux of FEL by combining ion-pair and chemical enhancer strategy. The optimized patch contained the adhesive Duro-Tak ${ }^{\circledR}$ 87-4098, 7\% FEL-TEA, and 10\% Azone, and it was used in further study.

\section{In Vivo Evaluation}

\section{Skin Irritation Test}

As was showed in Table III, the optimized FEL-TEA patch (containing 10\% Azone) produced no irritation to the rabbit skin compared with the standard irritant group. Skin irritation response depends on the amount of Azone released from the PSA layer. As a lipophilic enhancer, Azone had a good compatibility with the PSA and it appeared to have a lower release rate from the acrylic PSA without influence from the type of adhesive [39]. In this study, the acrylic type PSA Duro-Tak ${ }^{\circledR}$ 87-4098 was used as matrix, and therefore, not all Azone could be released from the optimal FEL-TEA patch in the administration period and the safety of using Azone could be assured [40].

\section{Pharmacokinetic Analysis}

To further evaluate the enhancement effect of combing ion-pair and chemical enhancer strategy, both the optimized FEL-TEA patch and commercial FEL patch SELTOUCH ${ }^{\circledR}$ were applied in rabbit to study their pharmacokinetics. Relevant profiles and parameters were presented in Fig. 10 and Table IV.

Compared to injection group, the MRT in FELTEA patch group was prolonged to $4.80 \pm 0.28 \mathrm{~h}$, which was more than seven times higher than that in injection group. This was believed to be due to the continuous replenishment of drug into the systemic circulation by constant drug delivery from transdermal patches. The MRT in FEL-TEA patch group $(4.80 \pm 0.28 \mathrm{~h})$ and FEL commercial patch group $(5.20 \pm 0.15 \mathrm{~h})$ showed no significant difference, but the FEL-TEA group achieved significantly higher $C_{\max }(2.23 \pm 0.49 \mu \mathrm{g} / \mathrm{mL})$ and $\mathrm{AUC}_{0-t}$ $(15.94 \pm 3.58 \mathrm{~h} . \mu \mathrm{g} / \mathrm{mL})$ values than the commercial patch group, which indicated the optimized FEL-TEA patch had higher skin permeation amount than the commercial product in vivo. The in vivo results also indicated
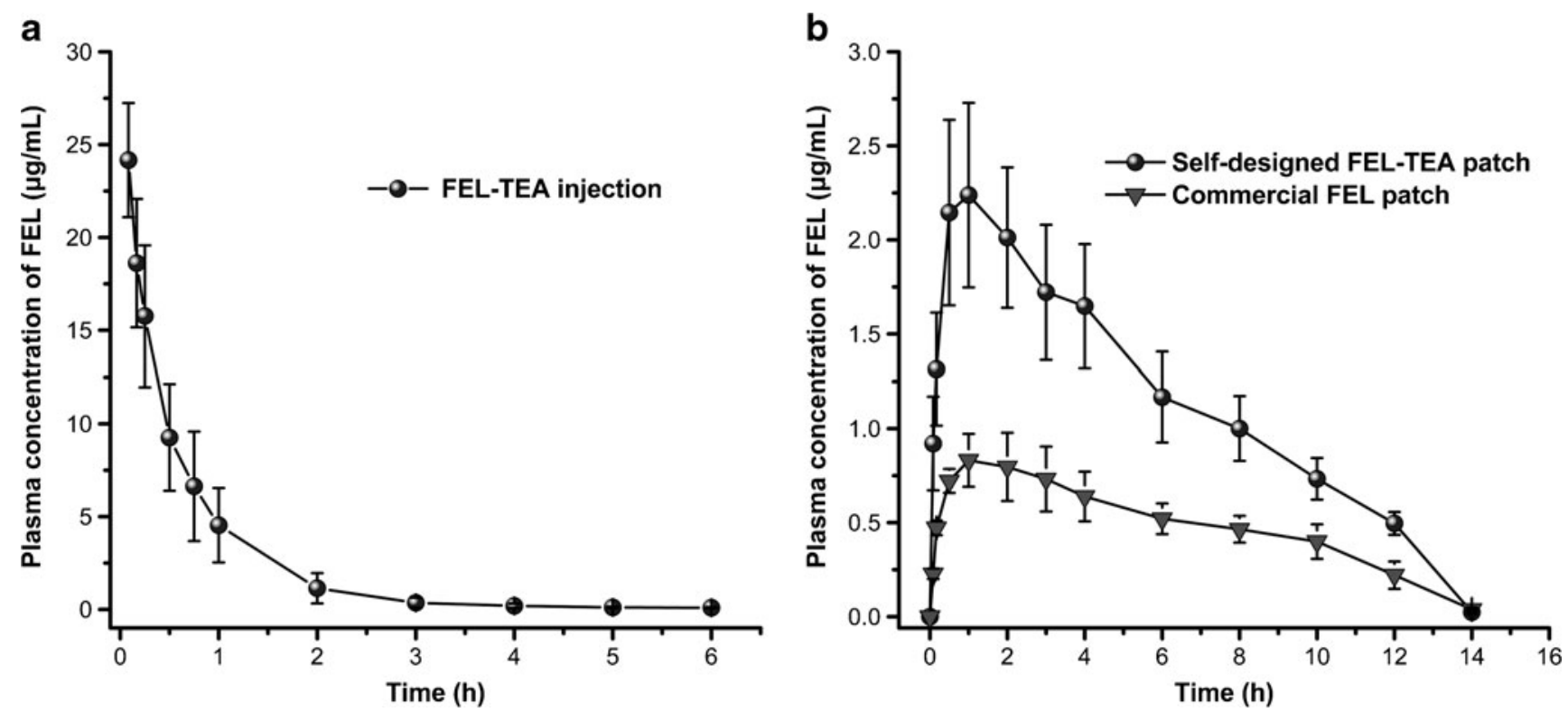

Fig. 10. a Plasma concentration-time profiles of FEL after intravenous injection of $8 \mathrm{mg}$ FEL (in the form of FEL-TEA) through ear marginal vein of rabbit $(n=4)$. b Plasma concentration-time profiles of FEL after transdermal administration of FEL-TEA patch and commercial FEL patch at the abdominal site of rabbit $(n=4)$ 
Table IV. Pharmacokinetic Parameters of FEL after Intravenous Injection and Transdermal Administration of Patches $(n=4)$

\begin{tabular}{|c|c|c|c|}
\hline \multirow[b]{2}{*}{ Parameters } & \multirow{2}{*}{$\begin{array}{l}\text { Intravenous } \\
\text { FEL-TEA }\end{array}$} & \multicolumn{2}{|l|}{ Transdermal } \\
\hline & & $\begin{array}{l}\text { FEL- } \\
\text { TEA patch }\end{array}$ & $\begin{array}{l}\text { Commercial } \\
\text { patch }\end{array}$ \\
\hline Dose of FEL (mg) & 8 & 24 & 24 \\
\hline$C_{\max }(\mu \mathrm{g} / \mathrm{mL})$ & $24.17 \pm 3.07$ & $2.23 \pm 0.49$ & $0.86 \pm 0.18$ \\
\hline $\mathrm{AUC}_{0-t}(\mathrm{~h} \cdot \mu \mathrm{g} / \mathrm{mL})$ & $16.18 \pm 3.74$ & $15.94 \pm 3.58$ & $7.31 \pm 1.16$ \\
\hline MRT (h) & $0.67 \pm 0.13$ & $4.80 \pm 0.28$ & $5.20 \pm 0.15$ \\
\hline
\end{tabular}

the feasibility of maximizing the flux of FEL by combining ion-pair and chemical enhancer strategy.

\section{In Vitro/In Vivo Correlation}

In vitro/in vivo correlation (IVIVC) is defined as a predictive model about the relationship between in vitro property of a dosage form and relevant in vivo performance [41]. For transdermal delivery, the in vitro property refers to the rate of skin permeation, and the in vivo performance is the drug concentration in plasma. In previous reports, IVIVC has been established for some drugs in topical preparations, and the deconvolution method showed a good prediction performance $[18,42,43]$.

Thus, based on the in vivo absorption data of FELTEA patch group and FEL-TEA injected group, in vitro skin permeation results were predicted by the deconvolution method with the help of WinNonlin ${ }^{\circledR}$. As was seen from Fig. 11, the predicted in vitro drug profiles were consistent with the actual observed in vitro profiles $(r=0.9951)$, which demonstrated that in vitro skin permeation studies could be used to predict the in vivo performance of FEL-TEA transdermal patches.

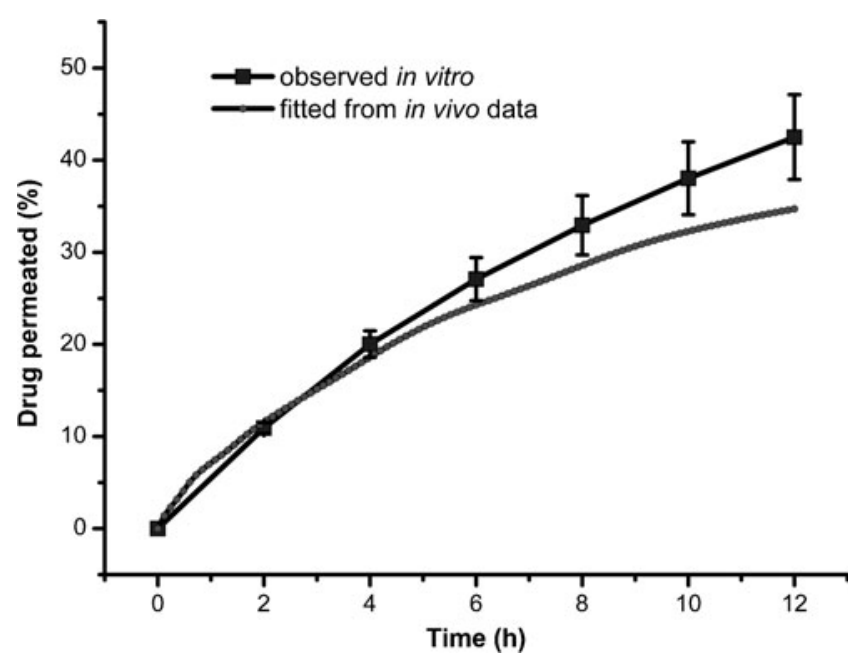

Fig. 11. Observed and fitted permeation profiles of FEL-TEA from transdermal patches through the rabbit abdominal skin in vitro

\section{CONCLUSION}

In this work, a novel transdermal patch of FEL was achieved by combining ion-pair and chemical enhancer strategy. The optimized patch containing FEL-TEA and $10 \%$ Azone had significantly higher skin permeation amount $(P<0.05)$ and $\mathrm{AUC}_{0-t}$ value than the product $\mathrm{SELTOUCH}^{\circledR}$ in vitro and in vivo. And furthermore, the in vitro skin permeation results of the optimized FELTEA patch were shown to be useful to predict the in vivo drug absorption profiles. Therefore, a combination of ion-pair and chemical enhancer strategy could be useful in developing a novel transdermal patch of FEL.

\section{REFERENCES}

1. Zhang C, Wang L, Yang W, Wang XS, Fawcett JP, Sun YT, et al. Validated LC-MS/MS assay for the determination of felbinac: application to a preclinical pharmacokinetics study of felbinac trometamol injection in rat. J Pharm Biomed Anal. 2009;50:41-5.

2. Heyneman CA, Lawless-Liday C, Wall GC. Oral versus topical NSAIDs in rheumatic diseases: a comparison. Drugs. 2000;60:555-74.

3. Hadgraft J, du Plessis J, Goosen C. The selection of non-steroidal anti-inflammatory agents for dermal delivery. Int J Pharm. 2000;207:31-7.

4. Shiba T, Shikata Y, Takagawa N, Sasaki M, Yanaka M, Sugiyama $\mathrm{Y}$, et al. Antiinflammatory and analgesic activities of felbinac adhesive preparation (felbinac patch). Jpn Pharmacol Ther. 1992;20:81-94.

5. Shinkai N, Korenaga K, Takizawa H, Mizu H, Yamauchi H. Percutaneous penetration of felbinac after application of transdermal patches: relationship with pharmacological effects in rats. J Pharm Pharmacol. 2008;60:71-6.

6. Leeb B. Topical felbinac in therapy of athletic injuries. Fortschr Med. 1994;112:77-80.

7. Dawson M, McGee CM, Vine JH, Nash P, Watson TR, Brooks PM. The disposition of biphenylacetic acid following topical application. Eur J Clin Pharmacol. 1988;33:639-42.

8. Tan HS, Pfister WR. Pressure-sensitive adhesives for transdermal drug delivery systems. Pharm Sci Technol Today. 1999;2:60-9.

9. Van der Windt DAWM, Van der Heijden GJMG, Van den Berg SGM, Ter Riet G, De Winter AF, Bouter LM. Ultrasound therapy for musculoskeletal disorders: a systematic review. Pain. 1999;81:257-71.

10. Bronaugh RL, Stewart RF. Methods for in vitro percutaneous absorption studies VI: preparation of the barrier layer. J Pharm Sci. 1986;75:487-91.

11. Agharkar S, Lindenbaum S, Higuchi T. Enhancement of solubility of drug salts by hydrophilic counterions: properties of organic salts of an antimalarial drug. J Pharm Sci. 1976;65:747-9.

12. Berge SM, Bighley LD, Monkhouse DC. Pharmaceutical salts. J Pharm Sci. 1977;66:1-19.

13. Williams AC, Barry BW. Penetration enhancers. Adv Drug Deliver Rev. 2012;64:128-37.

14. Zhang YX, Cun DM, Kong X, Fang L. Design and evaluation of a novel transdermal patch containing diclofenac and teriflunomide for rheumatoid arthritis therapy. Asian J Pharm Sci. 2014;9:251-9.

15. Cheong HA, Choi HK. Effect of ethanolamine salts and enhancers on the percutaneous absorption of piroxicam from a pressure sensitive adhesive matrix. Eur J Pharm Sci. 2003;18:149-53.

16. Hui M, Quan P, Yang YY, Fang L. The effect of ion-pair formation combined with penetration enhancers on the skin permeation of loxoprofen. Drug Deliv. 2014. doi:10.3109/ 10717544.2014.981768.

17. Draize JH, Woodard G, Calvery HO. Methods for the study of irritation and toxicity of substances applied topically to the skin and mucous membranes. J Pharmacol Exp Ther. 1944;82:377-90. 
18. Sun L, Cun DM, Yuan B, Cui HX, Xi HL, Fang L, et al. Formulation and in vitro/in vivo correlation of a drug-in-adhesive transdermal patch containing azasetron. J Pharm Sci. 2012;101:4540-8.

19. Katritzky AR, Jain R, Lomaka A, Petrukhin R, Maran U, Karelson M. Perspective on the relationship between melting points and chemical structure. Cryst Growth Des. 2001;1:261-5.

20. Mazzenga GC, Berner B. The transdermal delivery of zwitterionic drugs I: the solubility of zwitterions salts. J Control Release. 1991;16:77-88.

21. Chawla G, Gupta P, Thilagavathi R, Chakraborti AK, Bansal AK. Characterization of solid-state forms of celecoxib. Eur J Pharm Biopharm. 2003;20:305-17.

22. Arunan E, Desiraju GR, Klein RA, Sadlej J, Scheiner S, Alkorta I, et al. Defining the hydrogen bond: an account (IUPAC Technical Report). Pure Appl Chem. 2011;83:1619-36.

23. Xi HL, Wang ZY, Chen Y, Li W, Sun L, Fang L. The relationship between hydrogen-bonded ion-pair stability and transdermal penetration of lornoxicam with organic amines. Eur J Pharm Sci. 2012;47:325-30.

24. Van Eerdenbrugh B, Fanwick PE, Taylor LS. 2-(Biphenyl-4yl)acetic acid (felbinac). Acta Cryst. 2010;E66:O2609-U908.

25. Huheey JE. The electronegativity of groups. J Phys Chem. 1965;69:3284-91.

26. Liu NN, Zhang YQ, Cun DM, Quan P, Fang L. Effect of backing films on the transdermal delivery of donepezil from patches. AAPS PharmSciTech. 2014;15:1569-73.

27. Huyskens PL, Zeegers-Huyskens T. Molecular associations and acid-base equilibriums. J Chim Phys Phys Chim Biol. 1964;61:816.

28. Ma X, Fang L, Guo JP, Zhao NX, He ZG. Effect of counter-ions and penetration enhancers on the skin permeation of flurbiprofen. J Pharm Sci. 2010;99:1826-37.

29. Barrow GM. The nature of hydrogen bonded ion-pairs: the reaction of pyridine and carboxylic acid in chloroform. J Am Chem Soc. 1956;78:5802-6.

30. Megwa SA, Cross SE, Whitehouse MW, Benson HAE, Roberts MS. Effect of ion pairing with alkylamines on the in-vitro dermal penetration and local tissue disposition of salicylates. J Pharm Pharmacol. 2000;52:929-40.

31. Michaels AS, Chandrasekaran SK, Shaw JE. Drug permeation through human skin: theory and in vitro experimental. AICHE J. 1975;21:985-96.
32. Minghetti P, Cilurzo F, Casiraghi A, Montanari L, Fini A. Ex vivo study of transdermal permeation of four diclofenac salts from different vehicles. J Pharm Sci. 2007;96:814-23.

33. Auner BG, Valenta C, Hadgraft J. Influence of lipophilic counterions in combination with phloretin and 6-ketocholestanol on the skin permeation of 5-aminolevulinic acid. Int J Pharm. 2003;255:109-16.

34. Lane ME. Skin penetration enhancers. Int J Pharm. 2013;447:12-21.

35. Narishetty STK, Panchagnula R. Transdermal delivery of zidovudine: effect of terpenes and their mechanism of action. J Control Release. 2004;95:367-79.

36. Pilgram GSK, Van der Meulen J, Gooris GS, Koerten HK, Bouwstra JA. The influence of two azones and sebaceous lipids on the lateral organization of lipids isolated from human stratum corneum. Biochim Biophys Acta. 2001;1511:24454.

37. Sugibayashi K, Nakayama S, Seki T, Hosoya K, Morimoto Y. Mechanism of skin penetration-enhancing effect by Laurocapram. J Pharm Sci. 1992;81:58-64.

38. Díez-Sales O, Watkinson AC, Herráez-Domínguez M, Javaloyes $\mathrm{C}$, Hadgraft J. A mechanistic investigation of the in vitro human skin permeation enhancing effect of Azone ${ }^{\circledR}$. Int $\mathrm{J}$ Pharm. 1996;129:33-40.

39. Qvist MH, Hoeck U, Kreilgaard B, Madsen F, Frokjaer S. Release of chemical permeation enhancers from drug-inadhesive transdermal patches. Int J Pharm. 2002;231:25363.

40. Liu C, Fang L. Drug in adhesive patch of zolmitriptan: formulation and in vitro/in vivo correlation. AAPS Pharm Sci Tech. 2014. doi:10.1208/s12249-015-0303-3.

41. Uppoor VRS. Regulatory perspectives on in vitro (dissolution)/in vivo (bioavailability) correlations. J Control Release. 2001;72:127-32.

42. Qi X, Liu RR, Sun D, Ackermann C, Hou H. Convolution method to predict drug concentration profiles of 2,3,5,6tetramethylpyrazine following transdermal application. Int $\mathbf{J}$ Pharm. 2003;259:39-45.

43. Flynn GL, Shah VP, Tenjarla SN, Corbo M, DeMagistris D, Feldman TG, et al. Assessment of value and applications of in vitro testing of topical dermatological drug products. Pharm Res. 1999;16:1325-30. 